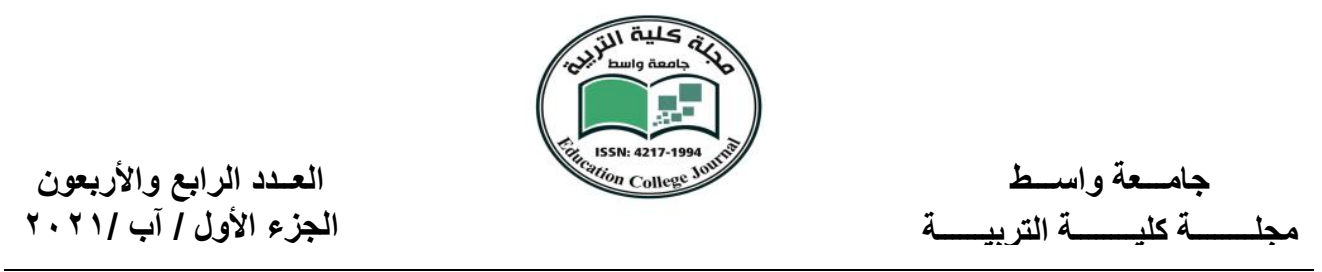

فاعلية الأنساق الأنثوية في شعر فاطمة محمود سعد الله

أ.م.د. رائدة مهدي جابر العامري جامعة بابل / كلية التربية الأساسية raydaalmry@gmail.com
أ.م.د. محمود خليف خضير الحياني

الجامعة التقنية الثمالية / العرلق

emaf_1979@yahoo.com

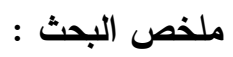

إن الأبجديات الأولى التي تجلت في قصيدة شمعةٌ في وجه الريح اشتغلت على منظومة لغوية

اتخذت من مسار الخطيئة التي التصقت بالأنثى عبر التاريخ طريقة في تجاوز نسق الإقصاء الذكوري ، فقد كانت عملية الهام التي بدأتها الثاعرة عن طريق فكرة الإرادة، والتحدي، والحرية، والتي تجسدت في عملية المخاض أو الولادة من رحم الكلمات، فالإشراقات، والتجلي، الذي اتخذ من الكلمة طريقة في التعبير عن فكرة الخلق، وتتظيم الأشياء وترتيبها وإعادة انتاجها من جديد في الخيال الثعري عن طريق اللغة، فتغير النسق المهيمن تم تعديله ،وتحويره ، وامتصاصه ، وتذويبه عن ولن طريق ابراز قدرة المرأة( الأنثى ) في الإبحار لعالم الكلمات الشعرية وموسيقى العروضية، فالقريح هي في في فئي بيت الوجود الجديد للأنثى، وتمركزها، التي بدأت تصهر كل المتعاليات وسلطة النسق الذكوري في لحظة، وصف المخاض والولادة، وهي في الأصل استعارة ، أو إثارة إلى أن هناك حضور أنثوي جديد يتم فيه تأثيث العالم الواقعي، الذي يمكن أن يتم تقويضه في عوالم الخيال الثعري الذي يظهر أثر الإشراق ، والوجد، الذي يعمل على غلب معادلة العدم إلى وجود بفعل الكتابة أو سلطة الكلمة التي ركزت عليها الثاعرة . مفاتيح الكلمات : تفكيك ، الانثى ، النسوية ، الحرف ، الصوت . 
العـدا الرابع والأربعون

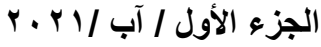
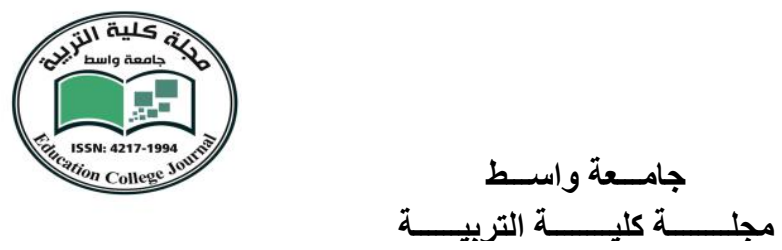

Research Summary :

The first alphabets that were evident in the poem Candle in the Face of the Wind worked on a linguistic system that took from the path of sin that has been attached to the female throughout history as a way to bypass the pattern of male exclusion, as it was the demolition process that the poet initiated through the idea of will, challenge, and freedom, which was embodied in The process of labor or birth from the womb of words, the brilliance and the manifestation, which took from the word a way to express the idea of creation, organize and arrange things and reproduce them again in the poetic imagination through language, so that the dominant pattern changed was modified, modified, absorbed, and dissolved by means of Highlighting the ability of the woman (the female) to navigate the world of poetic words and the music of performances, as Al-Raheeih is the home of the new existence of the female, and its centralization, which began to fuse all the transcendents and the authority of the male pattern in an instant. New in which the real world is furnished, which can be undermined in the worlds of poetic imagination, which shows the effect of radiance and solemnity, which works to overcome the equation of nothingness into existence by the act of writing or the authority of the word on which the poetess focused.

\section{Word keys:}

Dismantling, feminine, feminism, character, voice. 

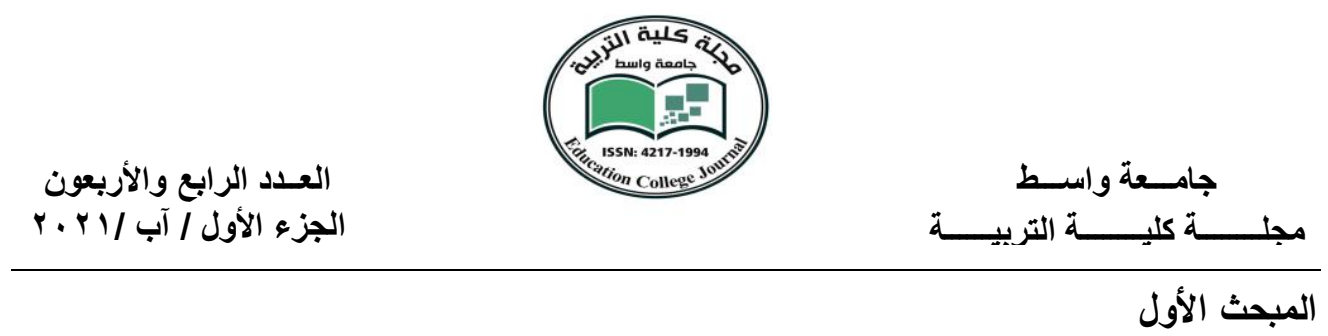

تفكيك الأصل الأنثوي في الخطاب النسوي

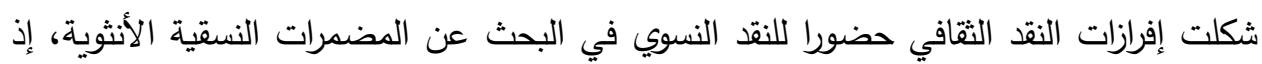

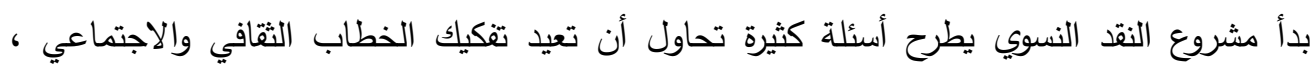

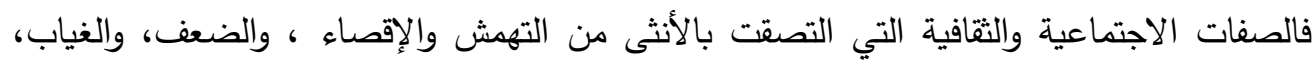

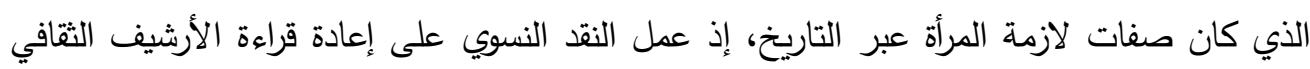

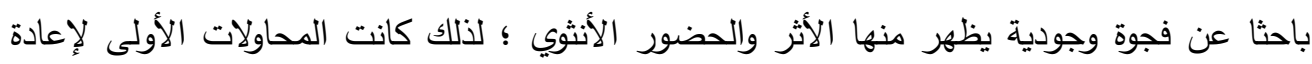

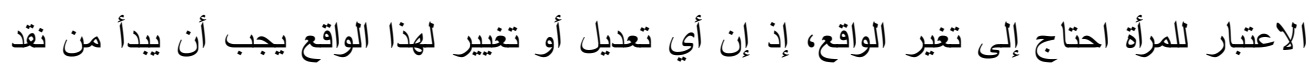

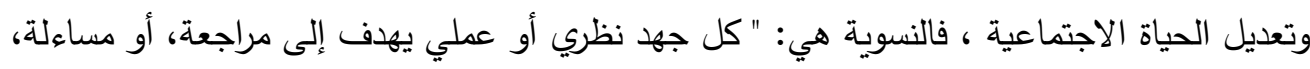

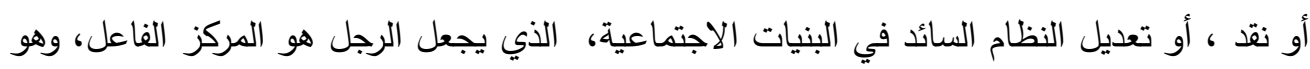

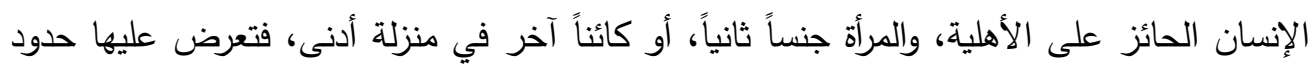

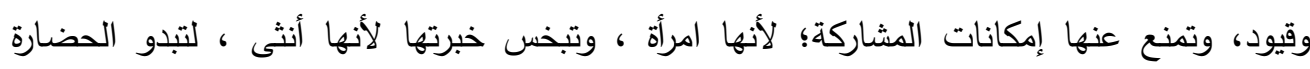

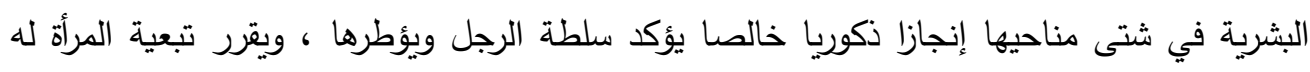

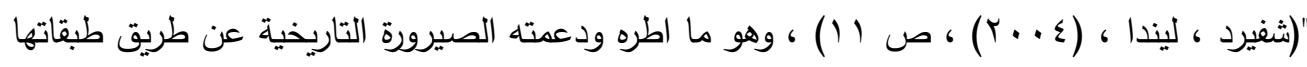

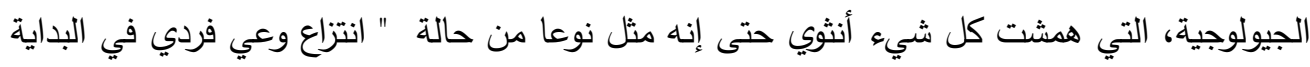
، ومن ثم وعي جمعي تتبعه ثورة ضد موازين القوى الجنسية والتهميش الكامل للنساء في لحظات إتهات

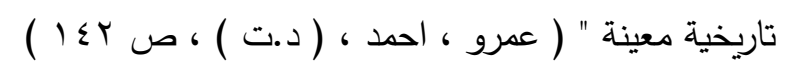

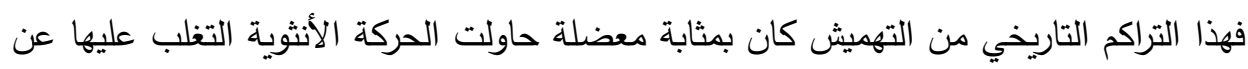

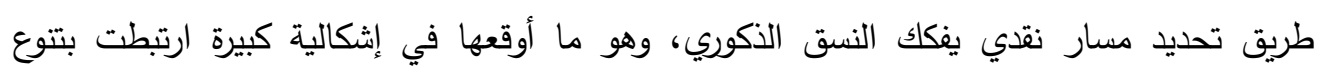

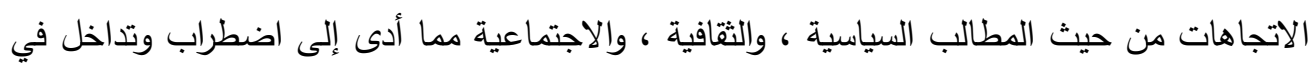

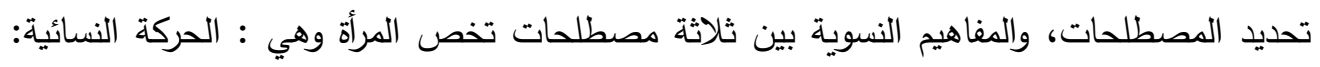

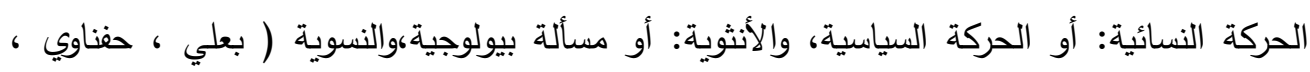

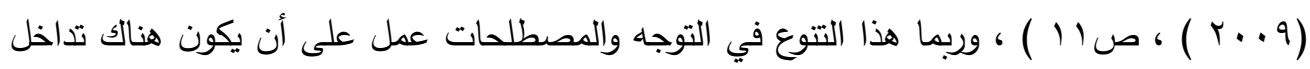

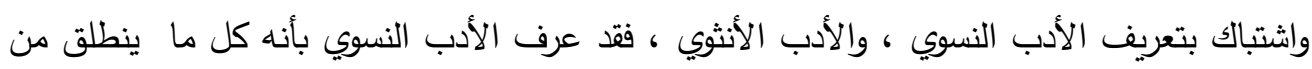

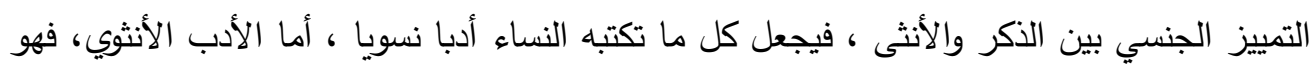

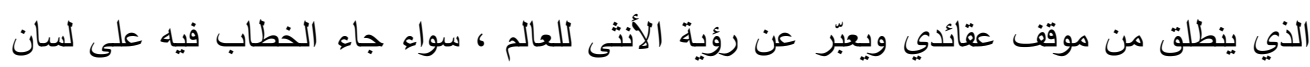

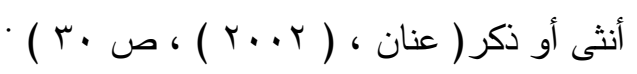


العـد الرغابع والأربعون

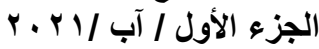
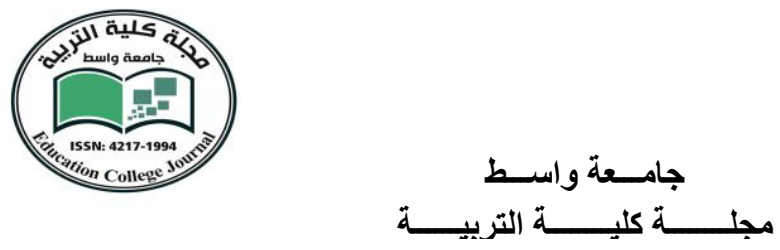

ولم يقتصر المخاض العسير في محاولة الاعتراف بالأدب، والنقد النسوي على الجانب

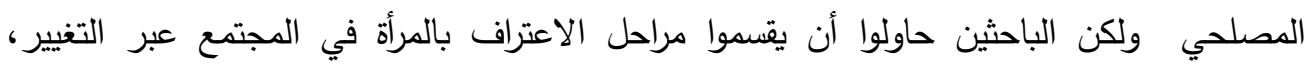

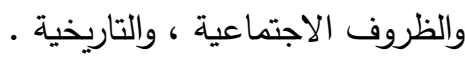

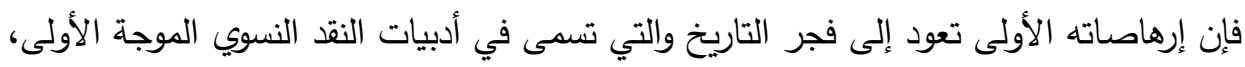

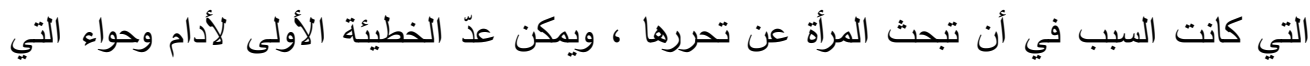

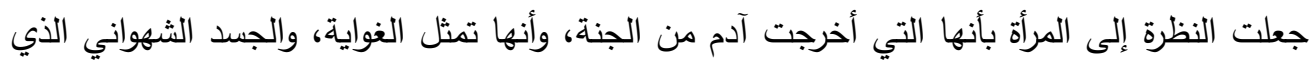

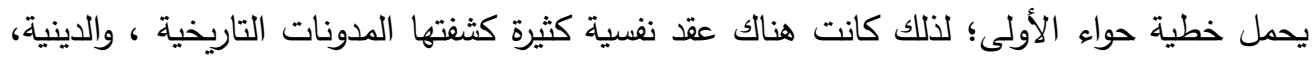

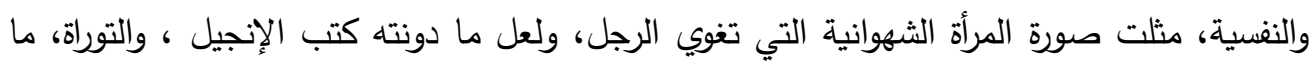

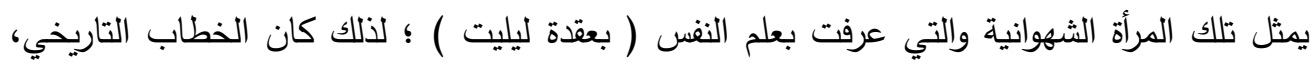

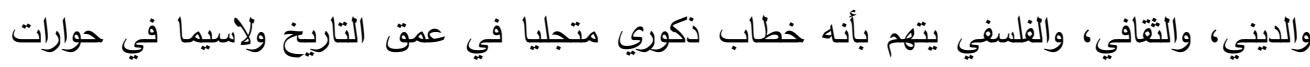

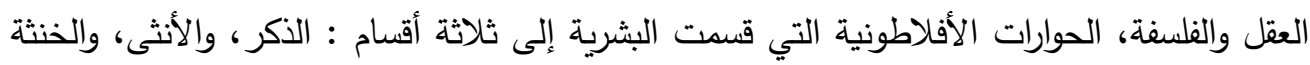

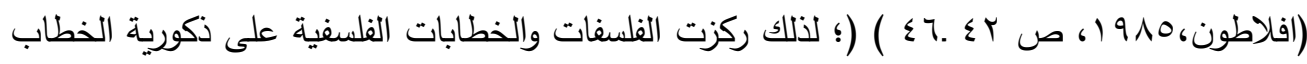

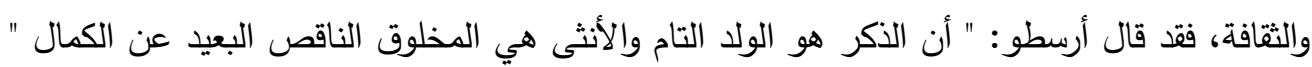

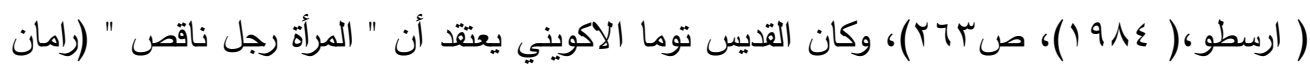

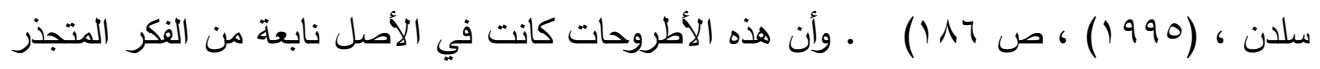

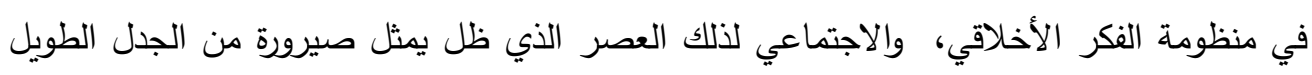

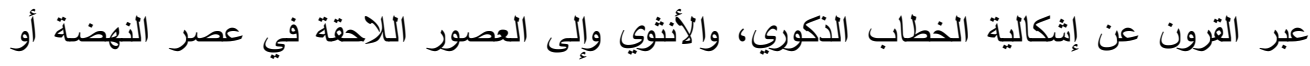

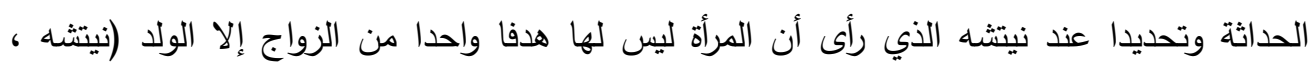

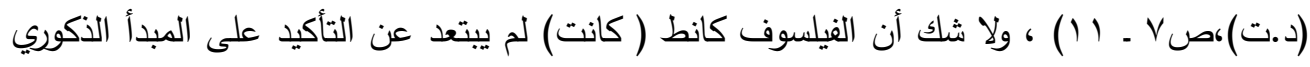

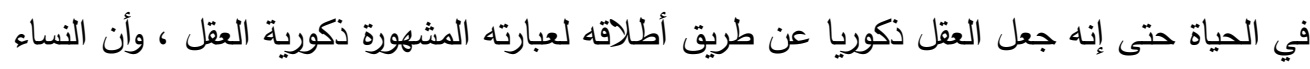

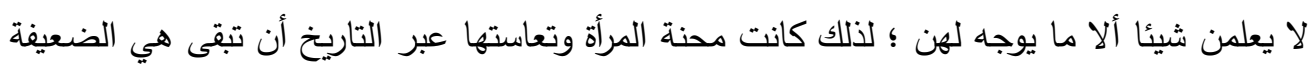

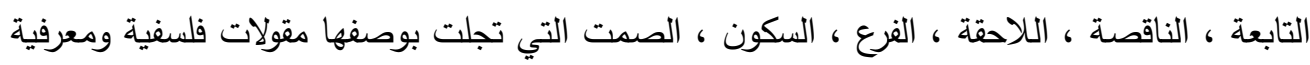

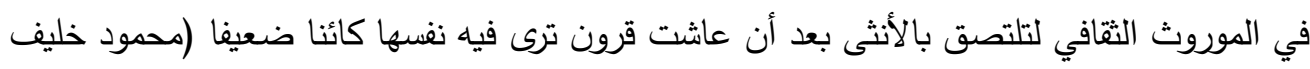

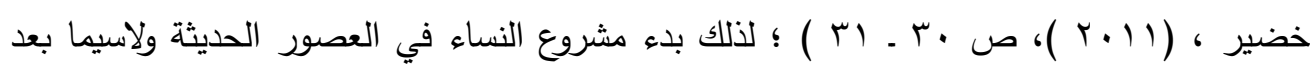

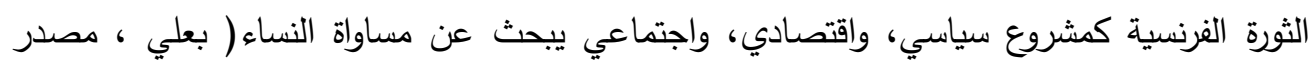

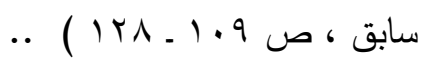


أما الموجة الثانية والتي أكدت على النقد النسوي فابتدأت من كتاب (غرفة فرجينيا وولف)،التي

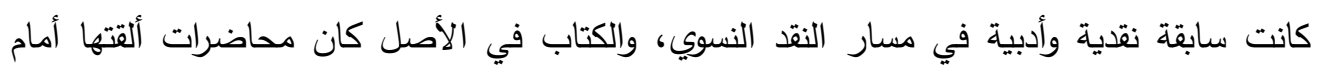

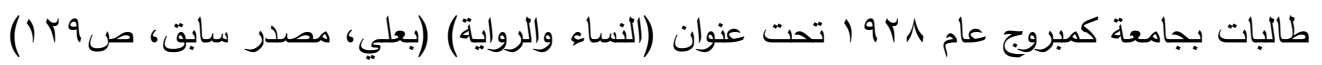

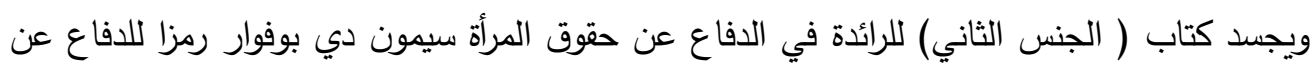
جود المرأة في الحياة .

ولقد طرحت المرحلة الثالثة، أو الموجة الثالثة في النقد النسوي، والتي جاءت بعد عام 1971 الثاء الذي مثل بداية ما بعد البنيوية أو ما بعد الحداثة مواضيع كثيرة دعت إلى تقويض المبل المعرفة السابقة وإعادة بنائها على وفق معطيات جديدة متطورة عن فكرة النقد النسوي القديمة المطالبة بالمساواة

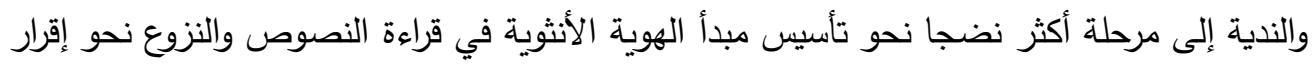

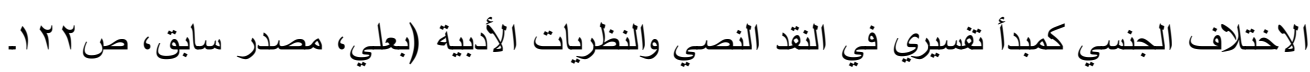
- (iro ولعلنا يمكننا التحدث اليوم عن ما بعد الحركة النسائية والتي عبرت عن حالة الهجوم على تفوق

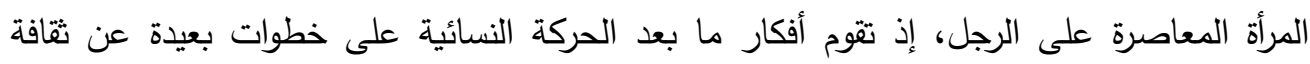

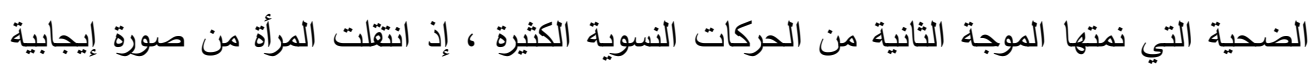

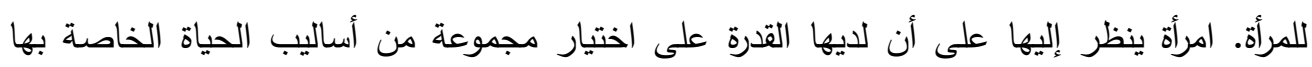

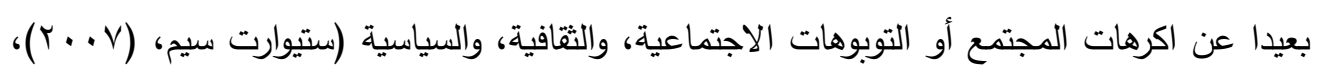

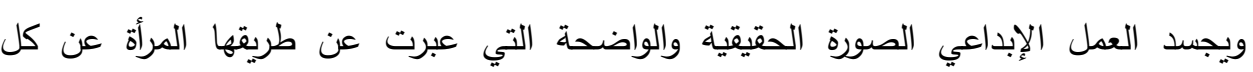
مكبوتات، واستلاب وتغيب، منتقدة النسق الذكوري عن طريق الإرادة، والتحدي ، وانعكاس المرآة الذاتية من المرآة المقعرة إلى المرآة المحدبة . 
التهديد بالانحراف عن أصل الخطيئة كانت متلازمة ذكورية وضعت الأنوثة في سلسلة النواقص أو عدم الاكتمال الذي بدأ بهجوط أدام بسبب غواية الأنثى، التي تمثل في كلمات أطلقتها حواء لكي تتحول إلى فعل براجماتي ينتج عنه أكل التفاحة، وينتهي بهبوط أدام وحواء (عليهما السلام) إلى الأرض ، فكانت الطبيعة القاسية في صالح الذكر وتحديد جسده القوي،الذي جسد كل مستلزمات القوة والعنف التي يحتاجها الإنسان في مجابهة الاحتياجات الضرورية للحياة، فالحاجة الحياتية هي التي تحدد موقع والرتيبة التي على أساسها تم حضور فكرة الهيمنة أو المركزية والهامش التي أدخلت الأنثى في جغرافية الحضر، والمحضور من حيث إنها الإنسان الناقص غير المكتمل الصامت

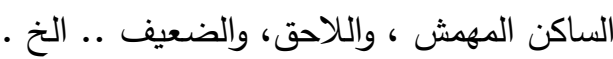
ومن الدلالة التي تجلت في محو الأثر الأنثوي عبر التاريخ ، والذي تم انتهاكه وتجازوه عن طريق البوح أو استراتيجيه الصوت التي بدأت تتغلب على خطيئة التهميش في فعل التحدي، والإرادة القوية والتي تكمل في كل حالة من النقص من طريق التمرد ، والنداء ، والبوح بالكلمات، فالثعر وبحوره هو بيت الوجود الأنثوي، الذي شكل كيميائية من الكلمات والحروف وأسرجتها التي أشعلت مضمار السابق، والتوجه إلى فرض تشكيل صوري أنثوي في الثعر العربي الحديث، فالإبعاد التي حطمت وحررت هاجس التمرد خرجت من أنفاس الصوت، ونداء، ومغامرة حقيقة تمثل الحضور الدائم، ففي قول الثاعرة فاطمة محمود سعد الله :

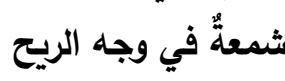
صؤت كأيّها الموْجُ.. يعلو ..هديراً.. مخاضاً... تولَلَّ بعده القصائدُ.. ينخفضُ.. -غنيماتٍ... تقطر همساً.. يورِقُ عُشْبةً نديّةَة. ببين شقوق الصخور.. تكتحلُ عيناها بالاخضرار... 


\section{جامسـعة واســـ

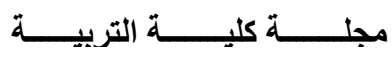

فتفكيك عنوان القصيدة (شمعةٌ في وجه الريح)، يشتغل على مستوى متوازي متتاقضة يجمع بين الضعف والقوة ، فالثدعة المتوهجة بوميض ضوء خافت يتحدى قوة وشدة الريح، فالتقابل بين الثمعة والريح يخالف منطق القوة والقدرة، ولكن يتغلب ضوء الثمعة في النهاية ، لأنها تمثل هي بصيص الضوء، والأمل الوحيد الذي يمكن أن يساعد هذه الأنثى الضعيف على البوح بإشراقات الكلمات وبراءتها، مرتفعة في حضرة ، ومقام السمو الصوت عن طريق ( صوْت كأيّها المؤج.. يعلو..هديراً..) ، فكثف الحجب أو الظهور الذي يشكله الصوت يغادر حضرة الصمت ، فهذا الصوت له انفعالات شديدة جدا محوله كموجة بحر متلاطما يعلو وينخفض ويكون هديرا صوتا قويا يبحث عن فسحة يريد

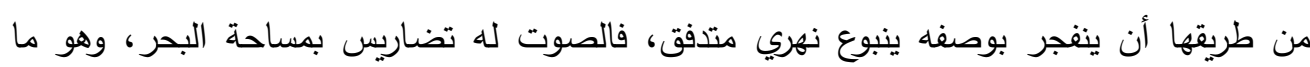

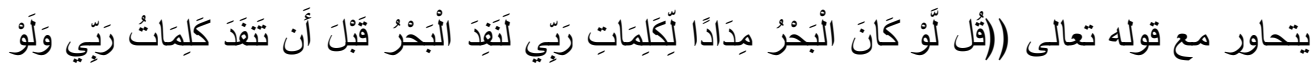

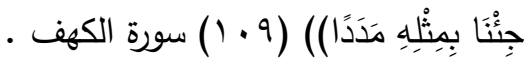
فالتموج والحركة تعبير عن شدة الانفعال ، والعاطفة الجياشة التي تحاول أن تثد المتلقي إليها مرتبطة بحبل سري من التقاعل والاستجابة لهذا التوتر العاطفي، لكي بعد ذلك يتجلى وينكثف هدير الماء بوصفه كلمات وأصوات ذات مخاضا، فالمخاض هو الولادة الجديدة لكل شيء يحتاج إلى قوة وإرادة ، فولادة الكلمة هي الجنين الذي يعبث بكل المقدسات كي يتحول إلى هيكل أو رسم مسار لبحور الثعر، والتي يطلق عليها القصائد ، فالكلمة لها عوالمها ، وحركتها وحياتها، فحركة البحر هارئ

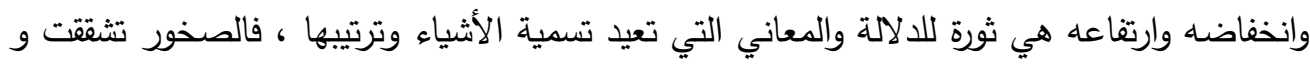
الأرض اخضرت ، فالكلمة الحر حياة واستقرار، وتحول من الغياب إلى حضور، الذي كله عطاء وخير وغواية دائمة ولذة ومتعة تغري مريدها للإفصاح في قولها :

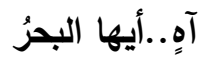
ملحُك يزيا عطثي إليك.. وجهُك السماويّ..

يروي فرشاتي.. تلك التي تغتسلُ بتعاويذِ الصمت.

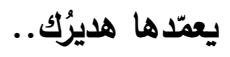
إلهاماً.. يملأ رَحِمَها ـ ـخُصوبةًة. . 
العزءد الاول ابع والأربعون

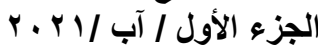

جامــعة واســـ كلــ

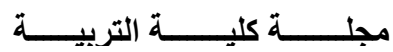

فنداء الألم ( آه ... أيها البحر ) هي للطلب والترجي لكون متعة النشوء، والتظيم، والترتيب، والتي تمارس دورا في إعطاء الكلمة صور وشكلا، فكلما كان البحر كريم في تدفق الكلمات من ظل الحجب إلى الظهور الذي ينتهك الصمت، فالكلمات تتناقض مع الصمت ، فبحضورها ينعدم الصمت ويكون في ظل الذاكرة والنسيان، فالكلمات لها هديرا وحركة وحياة ، فرحمها يحول الأشياء الميتة إلى خصوبة دائمة وإشراق وتوهجا ، أنها الأرض التي تستقي بالمشاعر ، والحب، واللعب ، والتمرد في قولها : تنجبُ أغمار الحروف..عند اللقاء ونرو

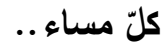

أناملُ الشمس . .تداعبُ صفْحتك الثفّافةً

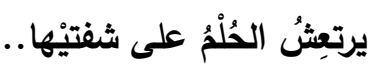
يزِْْرْ كفُّ المصافحةِ..مدّا ينثالُ على صذْرِ القمرِ.. الحروفُ لا تعرفِ الوداعُ. اللونُ يتنفّنُ الضياء..

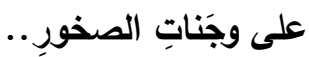

يشكل مجي اللغة مجي اللعبة عاملة على محو الحدود والتدفق والتضخم المستمر للدلالة،منظمة حركة مرور العلامة التي تتفتح على امتداد الدلالة يؤطر لتأثيث ينصهر فيه الحيز المكاني للصورة وفرشاتها التي ترسم بها الحروف وحدود الكلمات مع عبث اللغة وصيرورتها، فهي تجابه كل اطر متجاوز كل تحديد متخذة من قوالب الألوان والضياء ووجنات الصخور تشكيلات بصرية وسيميائية التي تتجلى فيها اشراقات الحلم ، فاللغة بوابة الحلم ومسرح أحداثه هي الأمل واليوتوبيا، والمستقبل الزاهي هي الحرية، والثثرة على كل الجامد والساكن، فهي البصمة والانطباع ، والأرشيف الذي يكون بفعل القلم، فهو سلاح الحرية في قولها : 

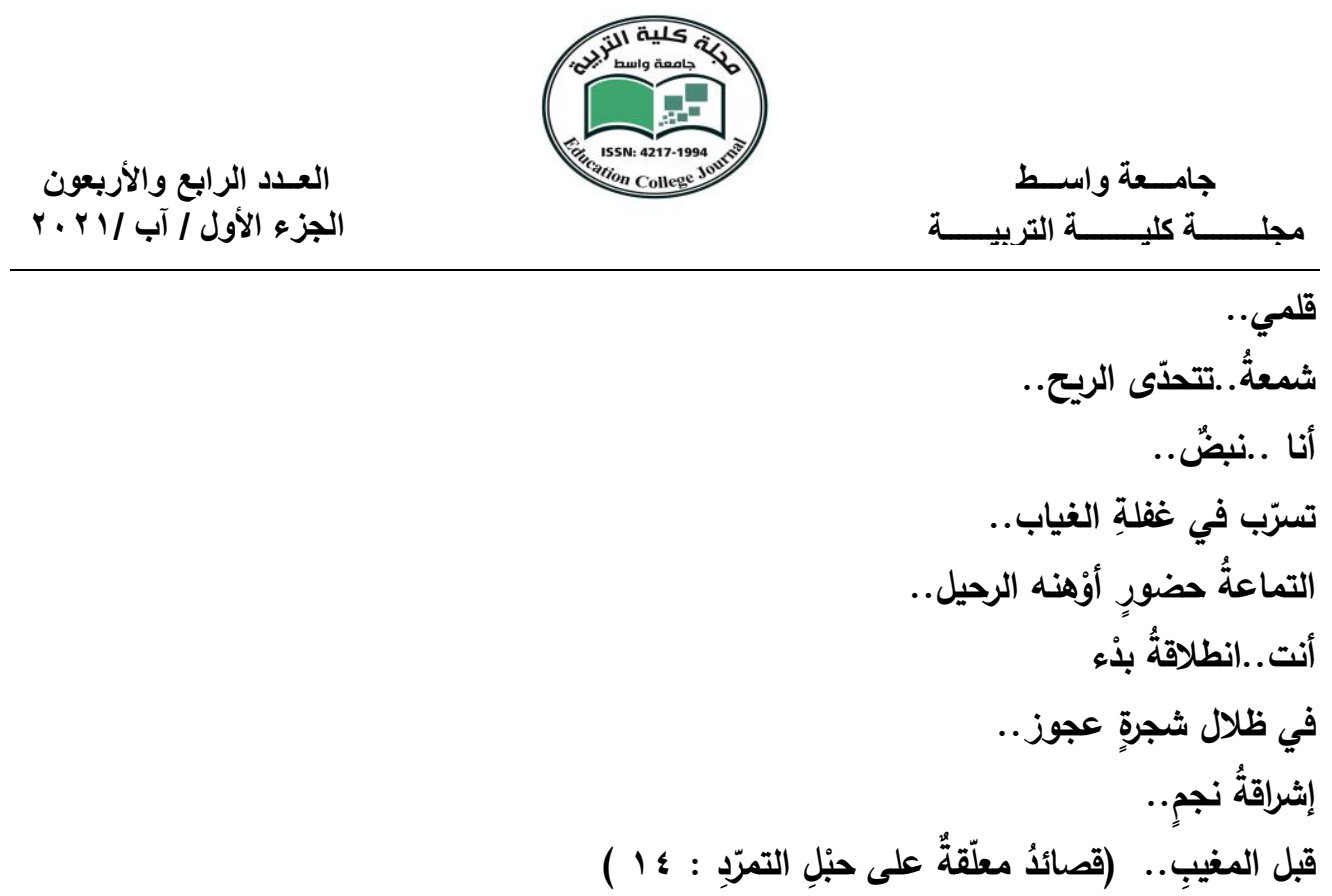

مفاتيح الإرادة الحرة هو فعل الكتابة بواسطة القلم ، فهو الذي يجسد الحضور ويتجاوز جدلية العدم والوجود ، فالقلم هو الوجود الذي ينبع منه المعرفة وتثكيل الأشياء، التي تكون في في عالم فئ الكتابة الذي يشكل الحضارة ويطوره ويفشي بالتقدم والازدهار ، متساوقا مع عملية الكثف أو التجلي، التي اعترفت بها الأنا في أن الثمعة التي تتحدى الريح أو كل المعوقات التي تحد من قدرة الأنا في الظهور ، فاختيار كلمة الرياح بصيغة الجمع تتشظى على شكل مجموعة كثيرة من المعوقات التي فرضت سلطتها ، وقدرتها في إقصاء وتغيب الأنا الأنثوية، منها السياسية، والثقافية ، والاجتماعية ، وأن عملية تقويضها من قبل الأنثى يحتاج إلى عملية تفكيك تمارس دور كبير في تبعثر ، وتثتت كل المقدسات أو المدنسات التي حافظت الحضارة الذكورية عليها، ولكن الانقلاب الذي تحاول الأنثى عن لون طريق الاستعانة بالقلم أن تعبث باه وتبعثره يتمظهر في هذا المقطع يجسد العمل الإبداعي الحر الذي يقدم الأنا ويغيب كل المعوقات ، والأنساق الثقافية الذكورية التي أخرست وأقصيت الأنا الحرة للأنثى

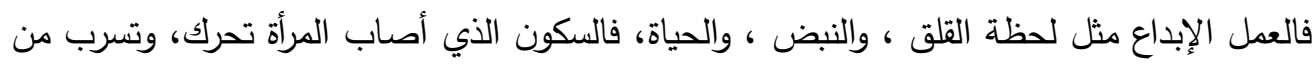
بين غفلة الغياب، ولعل كلمة الغفلة هي فسحة أو مسافة ضيقة من الحرية، التي وفرها العمل الإبداعي لكي تعبر المرأة عن حضوره بالكلمات بعيدا عن الحضور الجسدي المادي، فالإشراقات

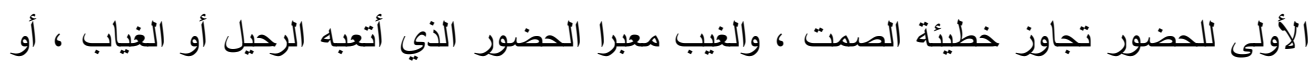
التهميش ، فالأثر الذي بقى من هذا المخاض تحول إلى وميض، أو نجم، أو ضوء ، والذي تجسد في ولادة القصيدة أو الفعل الحر الذي يتجاوز السور النفسي، والجسدي الذي أوجدته السلطة بكل أثكالها عبر التاريخ ، فالنجم هو السطوع ، والظهور البارز ، والخالد ، والباقي . 


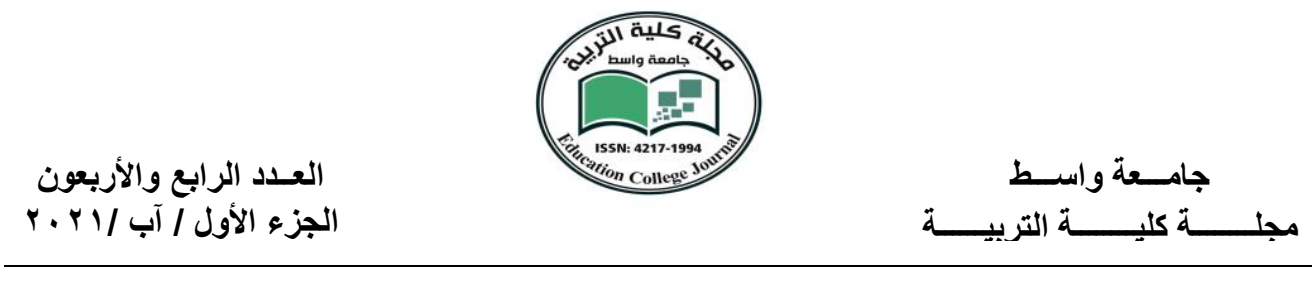

ولم تقتصر ثنائية الحضور والغياب فقط على الكلام والكتابة انما على ثنائية الاحتراق ما بين النار والنور في قوله : النار

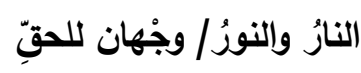

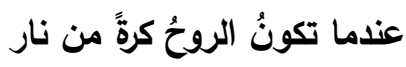

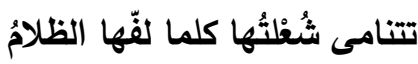

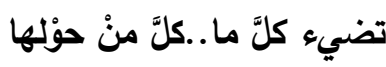

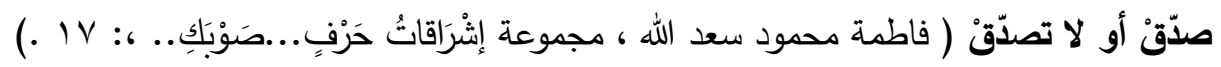
الانطباع الأولى الذي يتجلى في هذا المقطع الثعري هي قدرة النار المتقدة على انتشار أشعاعها

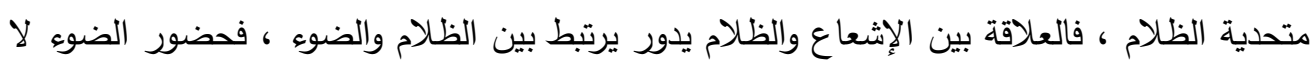

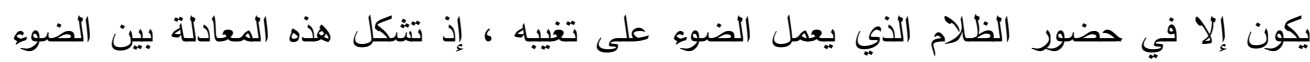

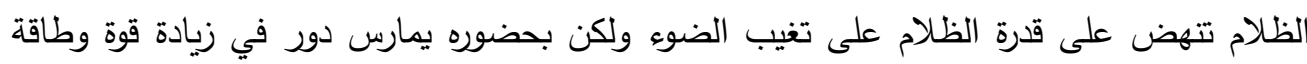

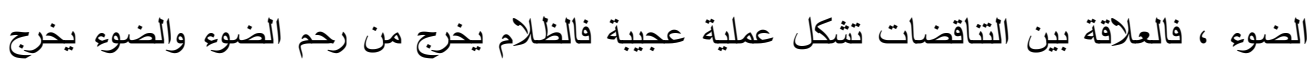

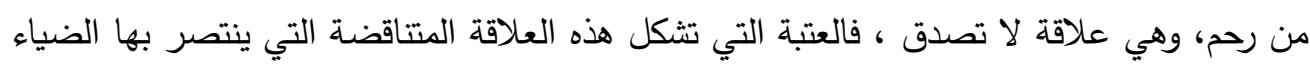

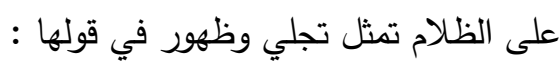

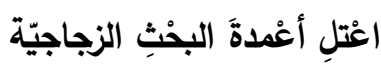
سترى قَلْبك اعتل يفيضُ بريقًا وسكينة وبهاء سترى الثمسَ تحرقُ كلَّ الثوائبٍ تصهُ الظلامَ . يتحوّلُ شموعًا تتحدّى أفاعي العَتمة وتقِفِ في وجُهِ التيّار

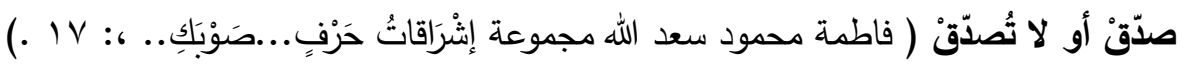

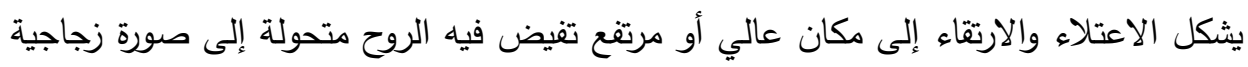

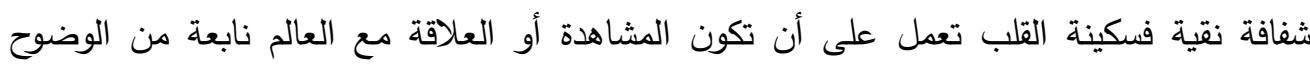

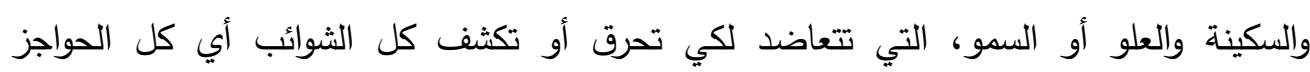

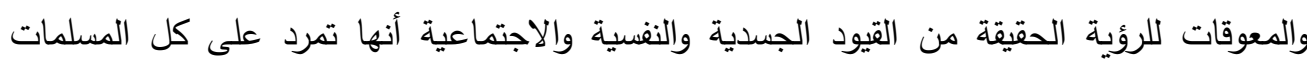




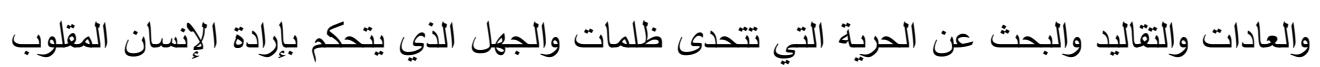

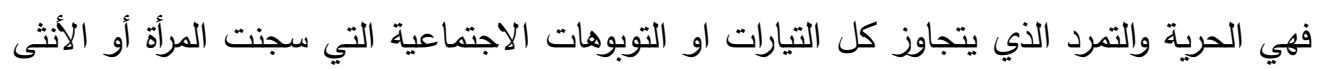

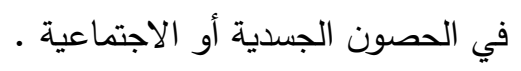
فالتغيب صفة ارتبطت بالأنثى حتى أصبحت جسد الأتماعد . بدون روح في قولها : r. (أنثى من رماد

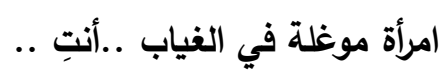

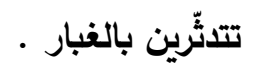

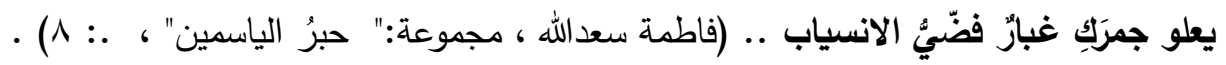

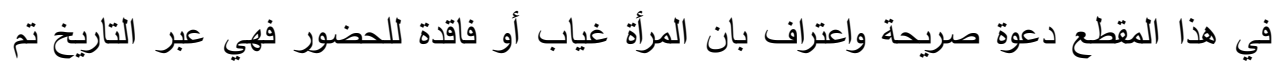

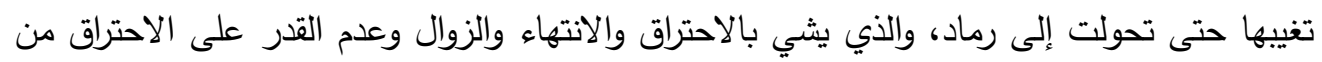

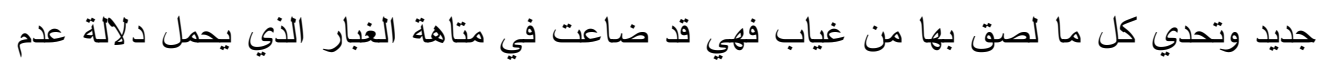

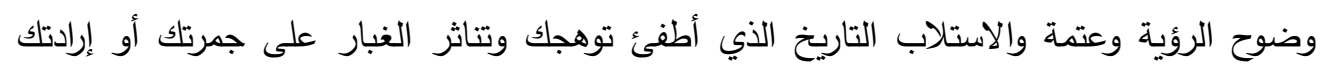
فأطفئ فادى إلى هذا التغيب فهي مشكلة اجتماعية وتاريخية في وقولها: أ.......

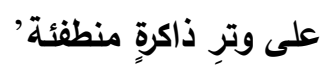
........ يباب.

تتسلّقين أسوارَ التذكّرِ الثاهقة ..

والقصر مرصود أيا أنثى .. من ضباب (فاطمة سعدالله ، مجموعة:" حبرُ الياسمين" ، .9 9) .

يبدأ النص بالنداء للأنثى العازفة إي المتمسك والكاشف عن ارث تاريخي وهوية مسلوبة وذاكرة

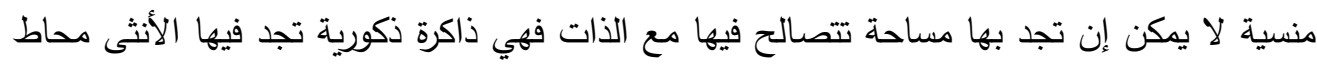

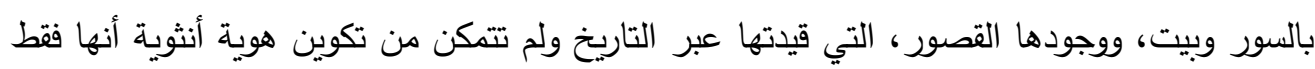
جارية تروي الحكايات العجيبة في قولها : 


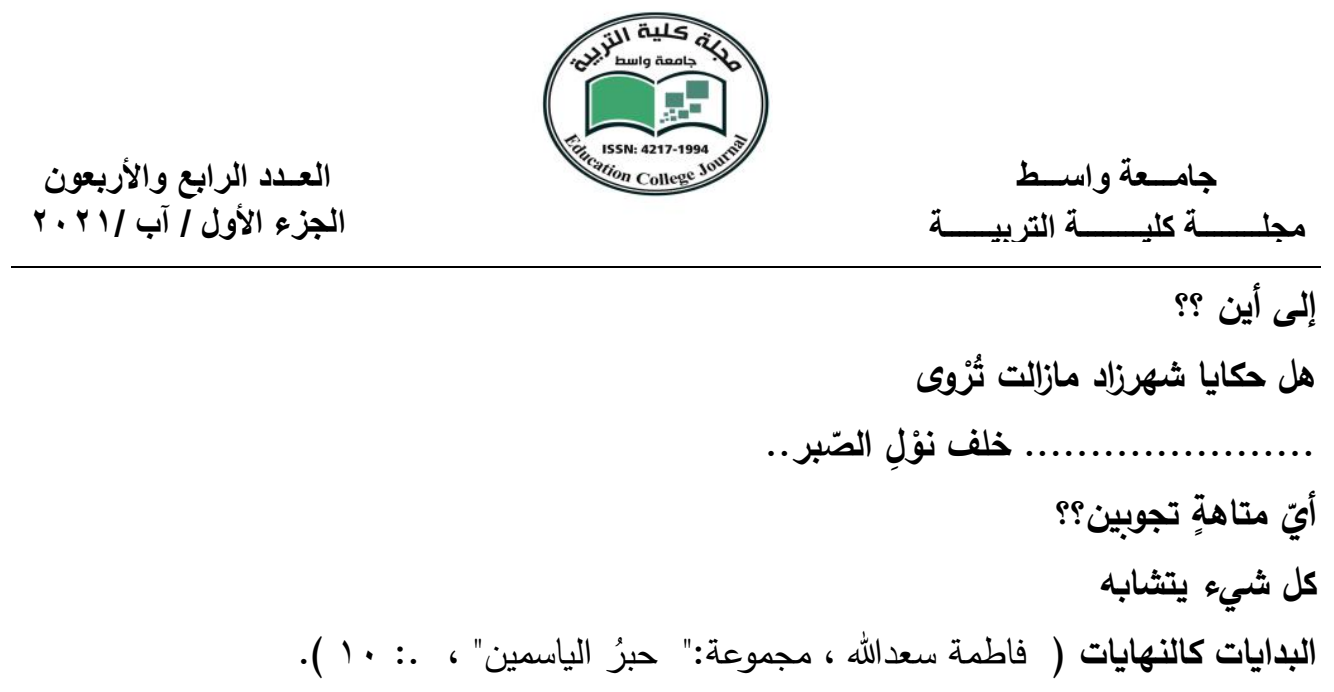

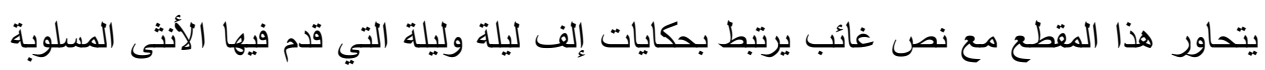

الخائنة التي لم تحافظ على قداسة التعاقد الاجتماعي مع شهريار فكان قتلها كل ليلية ولم تستطيع إن

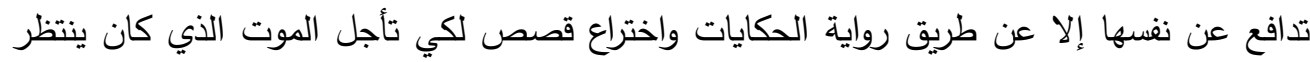

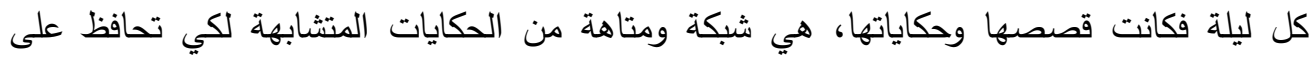
حياتها، فتثابهه الأيام وأصبحت البداية تتداخل بالنهاية متحولة إلى جارية مسلوبة الإرادة، يبحث عن

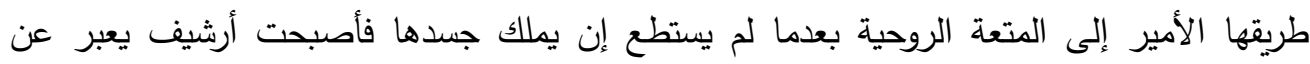

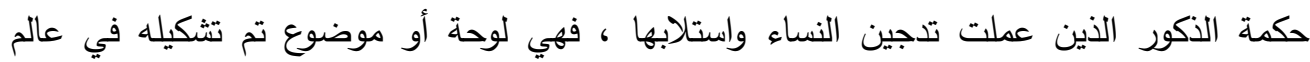

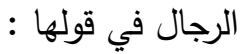

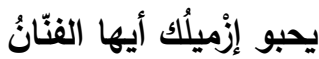
ينحتُ من الزّماد "جلاتيا" جديدة

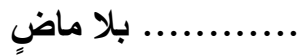

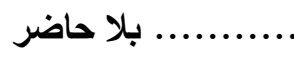

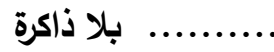
وعندما تتراكم خلجاتُ النبض.. يفخر "أبولو" وعنما تيرم ينفخ الروح والجمال يزهو "بيجماليون" عندما يفتلكّ الصولجان .. لروحمال وعند الأصيل ...

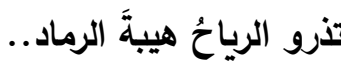
تذوب الأنثى ..وغبار الحنين .. تتلاثى الذاكرة العرجاء ... ( فاطمة سعدالله ، مجموعة:" حبرُ الياسمين" ، .و 9 . ) 
يتناص هذا النص مع أسطورة بجمال يونو النظرة الدونية للمرأة وما قدمته فلسفة الأسطورة من البحث عن الكمال أو الجمال في المرأة ، وقدرة عالم الرجال أو الذكور في تشكيل أو صنع تمثال امرأة كاملة ، أمرة صنعت من طينة وبمهارة الرجل بلا ذاكرة أو تاريخ أو حضور أو إرادة أو حرية ، فهي

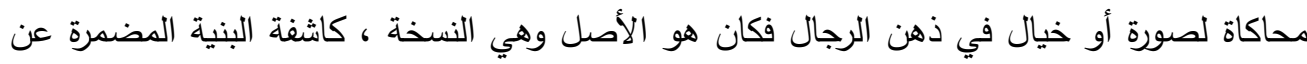

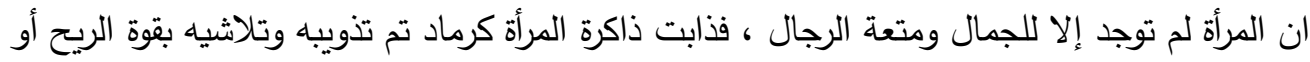
الثقافة التي كانت عملت على تعديمها وتذويبها وتغيب أرشيفها وذاكراتها وهوية وانتماء فكانت ذاكرة المرأة ذاكرة عرجاء ضعيف ومستلبة وليس لديها قدرة على الرفض والتمرد .

الخاتمة

ما تقدم في هذا البحث فانه كثف بأن خطيئة أكل التفاحة والتحريض الأنثوي على ذلك لم تكن هي الخطيئة الوحيدة ، إنما كان لها نتائج عملت على الإقصاء الأنثوي ، ووضعتها عبر مجموعة من هن الخطايا عبر التاريخ بوصفها التهميش ، والصمت ، والسكون ، والنقص ، واللاحقة، والتبعية، والضعف ، وأن أي نسق أنثوي يحاول أن يتجاوز هذه الانتهاكات يتم إبعاده أو تهميشه أو ترويضه في ديناميكية الثقافة الذكورية في علاقة القوة أو علاقة الغالب والمغلوب، وأن ما تطرحه هذه القصيدة من عملية تفكيك المركزيات الذكورية عن طريق البحث عن فعل الكتاب، أو العمل الحر الذي حاولت الثاعرة أن تغوص في أعماق البحور الثعرية باحثة عن الكلمات، والعبارة ، والإشارات، واللمحات الدالة التي تفكك وتبعثر، وتثتت عالم الأثياء أو الواقع في نظام اللغة ، ولعبة الكلمات التي خلت كل المركزية محولتها إلى تمركزات متتوعة أفرزت معادلة جديدة تشكل نصا موازيا للثقافة الذكوري تمثل في اشراقات وتتاصات وجدانية ، وشعورية تكثف عن العاطفة الجياشة التي يتمتع بها عالم الأنثى وقدرة الوجد الأنثوي في التعبير عن الحرية عن طريق عالم الإثارة، الذي تم تسجيله بوصفه أرشيف ذات اثر متوهج مثل النجم الساطع، فالظهور، والتجلي، والحضور ، كلها مفاهيم أظهرت مدى قدرة النسق الأنثوي في تحويل بحور الثعر ومخاضها إلى معادلة لصالح النسق الحر، وأن كان عن ولن طريق النقوش والطلاسم التي تمحو كل أثر للنسق الذكور عن طريق حضور الأنا الأثثوي بوصفها أنثى لها وجود ومركزية تبعدها عن الجسدي المادي الذي فرضها عالم السوق الاستهلاكي الاجتماعي والثقافي الذكوري ، فالكلم هي الوجود ، وفي البدا كانت الكلمة أنثى حرة ، وهو ما يمثل فلسفة هذه القصيدة التي تحدت كل التوبوهات والمقدسات في ثقافة الممانعة، والإقصاء، والترويض والديكتاتوري 
المصادر والمراجع : (المباج

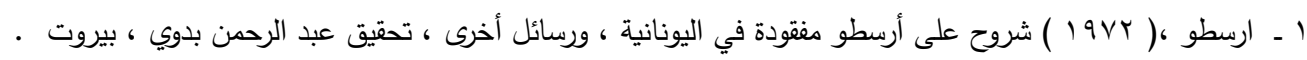

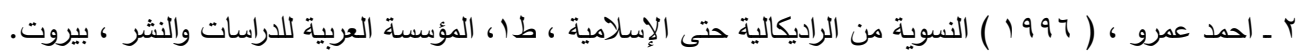

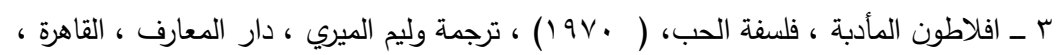

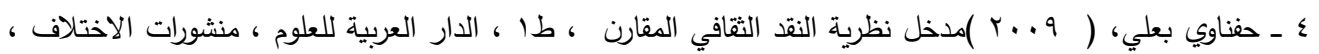
الجزائر ،

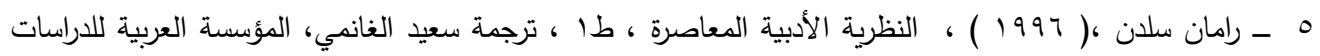

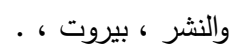

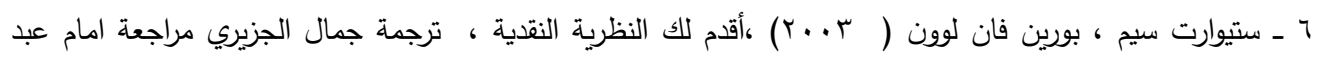

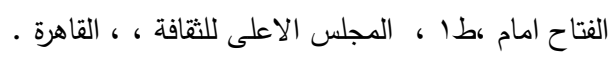

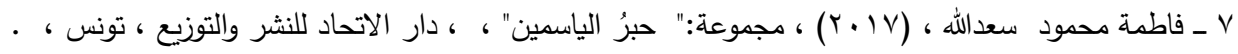

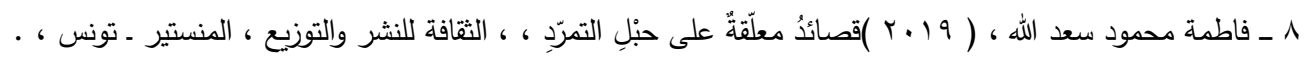

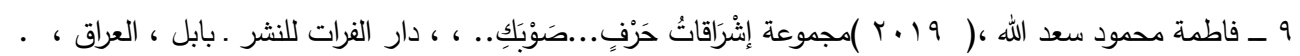

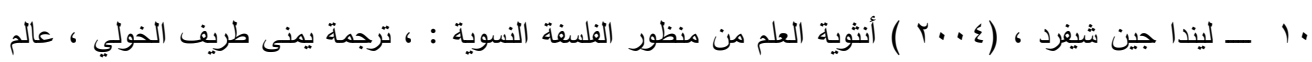

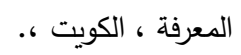

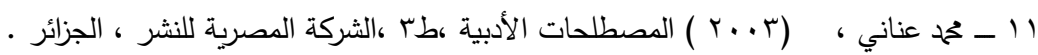

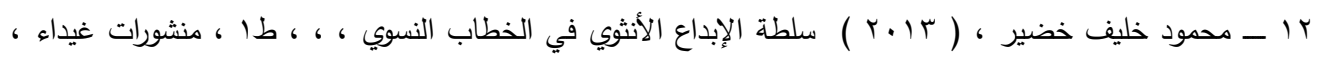

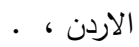
rا ـ ـ نيتثه ، ( د.ت ) العلم المرح ، ، ترجمة وتقديم حسان بورقية ، محمد التاجي ، افريقيا الثرق ، الجزائر . 